\title{
Modified Ryan Scheme for Tumor Regression
}

National Cancer Institute

\section{Source}

National Cancer Institute. Modified Ryan Scheme for Tumor Regression. NCI Thesaurus.

Code C155939.

A four-point tumor regression grading system that is used to measure therapeutic response of primary tumors and to predict patient outcomes. 